\title{
The Comparative Evaluation of the Antimicrobial Effect of Propolis with Chlorhexidine against Oral Pathogens: An In Vitro Study
}

\author{
A. Eralp Akca, ${ }^{1}$ Gülçin Akca, ${ }^{2}$ Fulya Toksoy Topçu, ${ }^{3}$ Enis Macit, ${ }^{4}$ \\ Levent Pikdöken, ${ }^{5}$ and I. Şerif Özgen ${ }^{6}$ \\ ${ }^{1}$ Faculty of Dentistry, Department of Periodontology, Istanbul Kemerburgaz University, Mahmutbey, 34217 Istanbul, Turkey \\ ${ }^{2}$ Gazi University Faculty of Dentistry, Department of Medical Microbiology, Emek, 06510 Ankara, Turkey \\ ${ }^{3}$ Gulhane Military Medical Academy, Center for Dental Sciences, Department of Restorative Dentistry, Etlik, 06010 Ankara, Turkey \\ ${ }^{4}$ Gulhane Military Medical Academy, Department of Analytical Toxicology, Etlik, 06010 Ankara, Turkey \\ ${ }^{5}$ Gulhane Military Medical Academy, Haydarpasa Training Hospital, Department of Dentistry, Section of Periodontology, \\ Haydarpasa, 34668 Istanbul, Turkey \\ ${ }^{6}$ Faculty of Dentistry, Department of Oral Surgery, Istanbul Kemerburgaz University, Mahmutbey, 34217 Istanbul, Turkey
}

Correspondence should be addressed to A. Eralp Akca; akcaeralpy@yahoo.com

Received 27 September 2015; Accepted 7 December 2015

Academic Editor: Satoshi Imazato

Copyright (c) 2016 A. Eralp Akca et al. This is an open access article distributed under the Creative Commons Attribution License, which permits unrestricted use, distribution, and reproduction in any medium, provided the original work is properly cited.

This study aimed to compare the antimicrobial effectiveness of ethanolic extract of propolis (EEP) to chlorhexidine gluconate (CHX) on planktonic Streptococcus mutans, Streptococcus sobrinus, Lactobacillus acidophilus, Lactobacillus salivarius subsp. salivarius, Aggregatibacter actinomycetemcomitans, Prevotella intermedia, Porphyromonas gingivalis, Staphylococcus aureus, Enterococcus faecalis, Actinomyces israelii, Candida albicans, and their single-species biofilms by agar dilution and broth microdilution test methods. Both agents inhibited the growth of all planktonic species. On the other hand, CHX exhibited lower minimum bactericidal concentrations than EEP against biofilms of A. actinomycetemcomitans, S. aureus, and E. faecalis whereas EEP yielded a better result against Lactobacilli and $P$. intermedia. The bactericidal and fungicidal concentrations of both agents were found to be equal against biofilms of Streptecocci, P. gingivalis, A. israelii, and C. albicans. The results of this study revealed that propolis was more effective in inhibiting Gram-positive bacteria than the Gram-negative bacteria in their planktonic state and it was suggested that EEP could be as effective as $\mathrm{CHX}$ on oral microorganisms in their biofilm state.

\section{Introduction}

Toothbrushing and interdental flossing are still basic methods to remove or to control bacterial plaque, which leads to the formation of caries and periodontal disease. However, the majority of the population may not perform the mechanical plaque removal sufficiently [1]. Thus, antimicrobial mouth rinses may provide an effective way of controlling bacterial plaque. It has been shown that chemotherapeutic mouth rinses are an effective adjunct to regular brushing and flossing [2].

Clinicians frequently administer CHX mouth rinses in order to inhibit the development of plaque $[3,4]$. However, the cytotoxic characteristics [5] and side effects [6] of CHX are the basic disadvantages that limit the administration of this pharmaceutical. Some manufacturers are in an attempt to produce natural oral care products from plant extracts in order to avoid the side effects of synthetic products. Among these natural products, propolis comes forward due to its antimicrobial activity against a wide range of Grampositive and Gram-negative pathogenic microorganisms [710]. Nevertheless, its effects against oral pathogens were compared to other oral antiseptics in a limited number of in vitro studies [11-13].

Propolis, also referred to as "bee glue," is the generic name for the resinous substance collected from various plant 
sources by honeybees (Apis mellifera). In nature, honeybees use propolis for structural sealing of the hive. Although this product has gained acceptance in folk medicine for a thousand years, it has been recently rediscovered by researchers [14]. The chemical composition of propolis varies depending on regional, seasonal, and vegetational changes in plant sources from which it is collected by the bees [8, 15]. The application of propolis against a broad spectrum of oral bacteria may be beneficial for improving oral health. In addition, current opinion is that the use of standardized preparations of propolis is safe and less toxic than many other synthetic drugs [16-20]. The results of these studies also indicated that flavonoids were the primary biologically active constituents of propolis extracts.

This study was undertaken to compare the in vitro antimicrobial efficiencies of propolis and CHX against planktonic strains and their biofilm forms of ten different oral bacteria and a yeast-like fungus, which were commonly seen in oral microflora.

\section{Material and Methods}

In this study, $0.2 \%$ of $\mathrm{CHX}$ oral rinse solution (Drogsan, Turkey) and the ethanolic extract of propolis (EEP) were applied on the strains of Streptococcus mutans ( $S$. mutans) ATCC\#25175, Streptococcus sobrinus (S. sobrinus) ATCC\#33478, Lactobacillus acidophilus (L. acidophilus) ATCC\#4356, Lactobacillus salivarius subsp. salivarius (L. salivarius subsp. salivarius) ATCC\#11741, Enterococcus faecalis (E. faecalis) ATCC\#29212, Staphylococcus aureus (S. aureus) ATCC\#25923, Aggregatibacter actinomycetemcomitans (A. actinomycetemcomitans) ATCC $\# 29523$, Actinomyces israelii (A. israelii) ATCC\#12102, Porphyromonas gingivalis (P. gingivalis) ATCC\#33277, Prevotella intermedia (P. intermedia) ATCC\#25611, and one yeast-like fungus: Candida albicans (C. albicans) ATCC\#10231. The minimum inhibitory concentration (MIC) and the minimum bactericidal concentration (MBC) for both antimicrobial agents were determined by conducting agar dilution and broth microdilution test methods.

2.1. Preparation of Propolis Extracts. The unrefined propolis (Apis mellifera) was obtained from Kazan/Ankara/Turkey. $20 \mathrm{~g}$ of unrefined propolis was accurately weighed (Shimadzu EB-330 EU, Japan) and dissolved in $100 \mathrm{~mL}$ of $80 \%$ ethanol (Sigma-Aldrich, USA) via ultrasonic bath at $40^{\circ} \mathrm{C}$ for 2 hours. The EEP solution was filtered through Whatman ${ }^{\circledR}$ and Protran ${ }^{\circledR}$ nitrocellulose membranes (Sigma-Aldrich, USA). The supernatant was evaporated by nitrogen flow until it dried. Approximately $5 \mu \mathrm{g}$ of residual substance was mixed with $75 \mu \mathrm{L}$ of dry pyridine and $50 \mu \mathrm{L}$ of bis-trimethylsilyl trifluoroacetamide (BSTFA), which was then heated at $80^{\circ} \mathrm{C}$ for $20 \mathrm{~min}$. The final supernatant was analyzed by gas chromatography mass spectrometry (GC-MS).

2.2. GC-MS Analysis. Extracted propolis substrates were dissolved in ethanol and analyzed in a GC-MS device (17A QP5050 model, Shimadzu, Japan). The GC was operated in splitless injection mode by utilizing a DB- 5 capillary column (length $=30 \mathrm{~m}$, internal diameter $=0.2 \mathrm{~mm}$, and film thickness $=0.1 \mathrm{~mm}$ ) with an injection port temperature at $250^{\circ} \mathrm{C}$. The carrier gas was helium at a flow rate of $50 \mathrm{~mL} / \mathrm{min}$. The column temperature was programmed so as to start from $60^{\circ} \mathrm{C}$ and increase up to $250^{\circ} \mathrm{C}$ in $15^{\circ} \mathrm{C} / \mathrm{min}$. increments. The initial and final time periods were 3 and 30 minutes, respectively. GC-MS was operated in full scan mode under $70 \mathrm{eV}$ in an electron ionization mode of ionization energy. The ion source temperature was $230^{\circ} \mathrm{C}$ and the capillary direct interface was heated up to $230^{\circ} \mathrm{C}$. The GC-MS peaks were identified by comparison to the data from Wiley 138 and Nist 98 libraries mentioned in the GC-MS program, which was supplied by the manufacturer. The chemical composition of EEP is given in Table 1.

2.3. Preparation of Microorganisms. S. mutans and S. sobrinus were cultured in $5 \mathrm{~mL}$ of brain heart infusion broth (BHIB, Oxoid, UK); L. acidophilus and L. salivarius subsp. salivarius were cultured in $5 \mathrm{~mL}$ of MRS Broth (DeMan Rogosa and Sharpe Medium, Merck, Germany) at $37^{\circ} \mathrm{C}$ for 48 hours in the microaerophilic atmosphere composed of $5 \% \mathrm{CO}_{2}$. E. faecalis and $S$. aureus were aerobically cultured in $5 \mathrm{~mL}$ of brain heart infusion broth (BHIB, Oxoid, UK) at $37^{\circ} \mathrm{C}$ for 48 hours. C. albicans was cultured in an autoclaved-sterilized Sabouraud dextrose broth (SDB, Oxoid, UK) at $37^{\circ} \mathrm{C}$ for 48 hours under aerobic conditions. A. actinomycetemcomitans, A. israelii, $P$. intermedia, and $P$. gingivalis were cultured in autoclaved-sterilized fastidious anaerobe broth (Lab M, UK) supplemented by sheep blood $(50 \mathrm{~mL} / \mathrm{L})$, vit. $\mathrm{K}(1 \mu \mathrm{g} / \mathrm{mL})$, and hemin $(5 \mu \mathrm{g} / \mathrm{mL})$ at $37^{\circ} \mathrm{C}$ for $6-7$ days in an anaerobic chamber (Electrotek, United Kingdom) in the atmosphere consisting of $90 \% \mathrm{~N}_{2}, 5 \% \mathrm{CO}_{2}$, and $5 \% \mathrm{H}_{2}$. The last three ingredients were filter-sterilized by a $0.22 \mu \mathrm{m}$ millipore before adding to the main medium. All freshly grown bacterial suspensions in $5 \mathrm{~mL}$ of their specific broth media were suspended to $1.5 \times 10^{8} \mathrm{CFU}$ (colony forming unit) $/ \mathrm{mL}$ according to the turbidity of $0.5 \mathrm{McF}$ arland test standard, and the concentrations of the bacterial/fungal suspensions were adjusted spectrophotometrically by using an automatic Elisa reader (ELx800, Biotek, USA) at an optical density of $600 \mathrm{~nm}$ $\left(\mathrm{OD}_{600}\right)$ to match the turbidity of all of the suspensions with 0.5 McFarland test standard.

2.4. Determination of the Minimum Inhibitory Concentration (MIC). The agar dilution method was used to evaluate the inhibitory effects of EEP and CHX. The MIC values were determined according to the guidelines by Clinical Laboratory Standards Institute (CLSI) [21, 22]. Serial twofold dilutions of EEP and CHX solutions were prepared under aseptic conditions. The final concentrations of the dilutions of each agent, which ranged from 1024 to $0.5 \mathrm{micrograms} / \mathrm{mL}$, were added to their specific agar media. Approximately $20 \mathrm{~mL}$ of the agar media was added to the sterilized plates $(100 \mathrm{~mm})$, which were prepared for each strain. All of the bacterial suspensions were cultured in their specific agar media plates and tested for the antimicrobial efficiencies of EEP and CHX dilutions. 
TABLE 1: Chemical composition of EEP.

\begin{tabular}{|c|c|c|}
\hline Chemical compound group & Chemical compound & $\%$ \\
\hline \multirow{4}{*}{ Aromatic alcohols } & Phenylethyl alcohol & 0.15 \\
\hline & Z,Z-2,6-Dimethyl-3,5,7-octatriene-2-ol & 0.12 \\
\hline & 2-Naphthalenemethanol & 0.8 \\
\hline & 4-(1,1-Dimethylethyl)-benzenemethanol & 0.05 \\
\hline \multirow{2}{*}{ Aromatic acids } & Benzoic acid, ethyl ester & 0.02 \\
\hline & 2-Hydroxy-6-heptadec-8Z,11Z,14Z-trienylbenzoic acid & 0.15 \\
\hline \multirow{3}{*}{ Aromatic heterocyclic alkaloid } & 6H-Benzofuro[3,2-c][1]benzopyran, 6a,1la-dihydro-3,4,8,9-tetramethoxy & 0.11 \\
\hline & 2-Trifluoromethyl-imidazole & 1.90 \\
\hline & 2-Trifluoromethyl-imidazole & 0.11 \\
\hline \multirow{8}{*}{ Cinnamic acid and its esters } & Hydrocinnamic acid, ethyl ester & 0.03 \\
\hline & Cinnamic acid & 0.04 \\
\hline & 3-Methoxycinnamic acid & 1.01 \\
\hline & Cinnamic acid, 3,4-dimethoxy methyl ester & 0.14 \\
\hline & 3,4-Dimethoxycinnamic acid & 1.57 \\
\hline & Ferulic acid & 0.08 \\
\hline & 3-Hydroxy-4-methoxycinnamic acid & 0.31 \\
\hline & m-Hydroxycinnamic acid & 0.91 \\
\hline \multirow{3}{*}{ Flavanone } & 5,7-Dihydroxy-dihydroflavone & 3.43 \\
\hline & Tectochrysin & 2.80 \\
\hline & 3,5,7-Trihydroxy- $4^{\prime}$-methoxyflavone & 0.08 \\
\hline \multirow{5}{*}{ Flavonones } & Chrysin & 12.06 \\
\hline & $4^{\prime}, 5$-Dihydroxy-7-methoxyflavanone & 0.65 \\
\hline & 4H-1-Benzopyran-4-one & 5.8 \\
\hline & Pinostrobin chalcone & 4.34 \\
\hline & Galangin & 2.20 \\
\hline \multirow{7}{*}{ Linear hydrocarbons and their acids } & Nonadecane & 0.05 \\
\hline & 2-Heptadecanone & 0.05 \\
\hline & 2-Nonadecanone & 0.26 \\
\hline & Octadecane & 1.69 \\
\hline & Nonadecane & 0.92 \\
\hline & Z-14-Nonacosane & 0.53 \\
\hline & 9-Hexacosene & 0.18 \\
\hline \multirow{12}{*}{ Naphthalene } & 1H-Cycloprop[e]azulene, decahydro-1,1,7-trimethyl-4-methylene & 0.05 \\
\hline & 3-Hydroxymyristic acid & 0.16 \\
\hline & Myristinic acid & 0.15 \\
\hline & cis-Oleic acid & 0.97 \\
\hline & Palmitic acid & 4.51 \\
\hline & Palmitic acid, ethyl ester & 0.49 \\
\hline & Z-7-Tetradecenoic acid & 0.11 \\
\hline & 1,9-Tetradecadiene & 0.12 \\
\hline & Oleic acid & 3.17 \\
\hline & Ethyl oleate & 2.05 \\
\hline & Stearic acid & 0.52 \\
\hline & Linoleic acid & 0.28 \\
\hline \multirow{2}{*}{ Unnatural amino acid derivatives } & 5-Aminovaleric acid & 0.25 \\
\hline & 5-Phenyl-4-pentenoic acid & 1.31 \\
\hline
\end{tabular}


S. mutans and S. sobrinus were incubated into trypticase soy agar (TSA, Difco, USA), which was supplemented with $20 \%$ sucrose $(\mathrm{w} / \mathrm{v})$, in the atmosphere composed of $5 \% \mathrm{CO}_{2}$ at $37^{\circ} \mathrm{C}$ for 48 hours. E. faecalis and S. aureus were aerobically incubated into $5 \%$ sheep blood agar at $37^{\circ} \mathrm{C}$ for 48 hours. $L$. acidophilus and L. salivarius subsp. salivarius were incubated into MRS agar (Rogosa, Merck, Germany) in the atmosphere consisting of $10 \% \mathrm{CO}_{2}$ at $37^{\circ} \mathrm{C}$ for 72 hours. Under aerobic conditions, C. albicans was incubated into Sabouraud dextrose agar (SDA, Oxoid, UK) at $37^{\circ} \mathrm{C}$ for 48 hours. $A$. actinomycetemcomitans, $A$. israelii, $P$. intermedia, and $P$. gingivalis were incubated into Colombia agar (Merck, Germany) $(41.0 \mathrm{~g} / \mathrm{L})$, which was supplemented with sheep blood $(50$ milliliters $/ \mathrm{L})$, vit. $\mathrm{K}(1 \mu \mathrm{g} / \mathrm{mL})$, and hemin $(5 \mu \mathrm{g} / \mathrm{mL})$, at $37^{\circ} \mathrm{C}$ in anaerobic chamber $\left(90 \% \mathrm{~N}_{2}, 5 \% \mathrm{CO}_{2}\right.$, and $\left.5 \% \mathrm{H}_{2}\right)$ for 4-5 days. The MIC values for all of the test bacteria were defined as the lowest concentrations of EEP and CHX, which inhibited the visible growth of microorganisms. The agar plates, which did not contain EEP and CHX solutions and the ethanol solution of $80 \%$, were used as controls.

By using the same EEP and CHX concentrations (ranging from 1024 to $0.5 \mu \mathrm{g} / \mathrm{mL}$ ), all of the test microorganisms were also analyzed by broth microdilution method. The purpose of this reanalysis was to corroborate the MIC results obtained by both methods and to find out the exact MBC/MFC values. 96-well microplates were used in the broth microdilution method. In this method, the dilutions of $0.1 \mathrm{~mL}$ of EEP and $\mathrm{CHX}$, which were suspended in concentrations ranging from 1024 to $0.5 \mu \mathrm{g} / \mathrm{mL}$, were added to microplate wells. Subsequently, the $0.1 \mathrm{~mL}$ suspension of each microorganism in its specific broth media, which was prepared for the agar dilution method, was added to microplate wells containing $100 \mu \mathrm{L}$ of different concentrations of EEP and CHX. In order to determine the MIC values, the incubations were carried out in accordance with the same aerobic, microaerophilic, and anaerobic conditions and time intervals as mentioned before.

\subsection{Determination of the Minimum Bactericidal Concen-} tration $(M B C)$ and the Minimum Fungicidal Concentration (MFC). The MBC and MFC were determined by subculturing the $50 \mu \mathrm{L}$ of aliquots into their specific agar media. The aliquots were obtained from each microplate well in which no visible growth of microorganisms was noticed. The plates were incubated and cultured in the same conventional microbiological conditions and incubation periods as described before and were evaluated according to the guidelines of CLSI.

The $80 \%$ of ethanol was used as control against planktonic strains and the microbial biofilm of them. The results were expressed both in MIC and in MBC values. All tests were performed in duplicate.

2.6. Preparation of the Biofilms of the Test Microorganisms. Single-species biofilm of the microorganisms was generated on nitrocellulose membranes with $0.22 \mu \mathrm{m}$ pore size, $13 \mathrm{~mm}$ diameter (F7148, Sigma, USA), and then they were put on the flat-bottom 24-well tissue culture plates (3574, Corning Costar, USA). A volume of $100 \mu \mathrm{L}$ of each bacterial and fungal suspension, which were suspended according to the turbidity of $0.5 \mathrm{McF}$ arland standard as a concentration of $1.5 \times$ $10^{8} \mathrm{CFU} / \mathrm{mL}$, was added to the surface of membranes and incubated for $30 \mathrm{~min}$. Then $1 \mathrm{~mL}$ of their specific broth media as mentioned before was added to the wells. The plates were covered up and the microorganisms were cultured in their specific broth media and at the same atmospheric conditions as described before. The plates were put in the incubators with $5 \% \mathrm{CO}_{2}$ for Streptococci and Lactobacilli and without $5 \% \mathrm{CO}_{2}$ for $S$. aureus, E. faecalis, and C. albicans for 1 week. For $A$. actinomycetemcomitans, $P$. gingivalis, $A$. israelii, and $P$. intermedia, the culture plates were prepared in an automatic anaerobic chamber (Electrotek, UK) and incubated for at least 10 days in anaerobic conditions $\left(10 \% \mathrm{H}_{2}, 10 \% \mathrm{CO}_{2}\right.$, and $80 \% \mathrm{~N}_{2}$ ) at $37^{\circ} \mathrm{C}$. During their incubation period the broth media were meticulously changed with the fresh one in every two days avoiding touching the bottom of the wells. The tests were carried out in triplicate for each agent and microorganism. After incubation, the formation of biofilm was controlled by staining one of the membranes with $1 \%$ of safranin for each strain and evaluated microscopically. After the formation of biofilm layer, $1 \mathrm{~mL}$ solution of both test agents was put into the wells including the media at the concentrations of $1 / 2$ diluted ranges as described and prepared before. The membranes were then discarded gently from the wells of the plates and were washed with PBS ( $\mathrm{pH}: 7$ ) 3 times. The membranes were then taken and put into other tubes including $1 \mathrm{~mL}$ PBS. Tubes were vortexed for $1 \mathrm{~min}$. The suspensions inside the tubes were diluted $10^{-4}, 10^{-5}$, and $10^{-6}$. Then, $100 \mu \mathrm{L}$ of each diluted suspension was put into plates including their specific agar media for each microorganism. After incubating at the same specific conditions for each strain the viable colonies of microorganisms were determined as $\mathrm{MIC}$ and $\mathrm{MBC} / \mathrm{MFC}$ values.

\section{Results}

The EEP solution inhibited the growth of all planktonic species as much as CHX except $P$. gingivalis and A. actinomycetemcomitans (Table 2). The effect of EEP was not related to $80 \%$ of ethanol since it did not affect the growth of any bacteria and the fungus. In addition, EEP was more effective against Gram-positive bacteria and C. albicans than Gramnegative bacteria. Among the anaerobic bacteria, EEP seemed to be more effective on $P$. intermedia than $\mathrm{CHX}$.

The analysis of the biofilms of tested microorganisms revealed that both test agents were not as effective as they were on planktonic species (Table 3). However, the concentration of both agents was found to be sufficient to manifest a bactericidal effect on tested bacteria and fungus except $S$. mutans, S. sobrinus, and A. israelii, which can be accepted as pioneer microorganisms in the formation of microbial dental plaque. The bactericidal effect of EEP was better than that of CHX on L. acidophilus, L. salivarius subsp. salivarius, and $P$. intermedia. The strongest effect of EEP was observed on C. albicans and E. faecalis. On the other hand, CHX was more bactericidal than EEP against $S$. aureus, A. actinomycetemcomitans, and E. faecalis. 
TABLE 2: MIC and MBC/MFC values of EEP and CHX on the planktonic test microorganisms $(\mu \mathrm{g} / \mathrm{mL})$.

\begin{tabular}{|c|c|c|c|c|}
\hline Strains & $\begin{array}{c}\text { Agar dilution } \\
\text { EEP (MIC/MBC) }\end{array}$ & $\begin{array}{c}\text { Broth microdilution } \\
\text { EEP (MIC/MBC) }\end{array}$ & $\begin{array}{c}\text { Agar dilution } \\
\text { CHX (MIC/MBC) }\end{array}$ & $\begin{array}{c}\text { Broth microdilution } \\
\text { CHX-MIC/MBC }\end{array}$ \\
\hline S. mutans & $4 / 8$ & $4 / 8$ & $8 / 16$ & $16 / 16$ \\
\hline S. sobrinus & $8 / 8$ & $4 / 8$ & $8 / 8$ & $8 / 16$ \\
\hline L. acidophilus & $4 / 4$ & $4 / 8$ & $8 / 8$ & $4 / 8$ \\
\hline L. salivarius subsp. salivarius & $2 / 4$ & $2 / 4$ & $4 / 4$ & $2 / 4$ \\
\hline A. actinomycetemcomitans & $64 / 128$ & $64 / 128$ & $32 / 16$ & $16 / 32$ \\
\hline P. intermedia & $8 / 8$ & $8 / 8$ & $16 / 16$ & $16 / 16$ \\
\hline P. gingivalis & $32 / 64$ & $32 / 64$ & $8 / 16$ & $16 / 32$ \\
\hline S. aureus & $16 / 16$ & $8 / 16$ & $16 / 16$ & $16 / 32$ \\
\hline E. faecalis & $8 / 8$ & $4 / 8$ & $8 / 8$ & $8 / 16$ \\
\hline A. israelii & $16 / 16$ & $8 / 16$ & $16 / 16$ & $8 / 16$ \\
\hline C. albicans & $16 / 16$ & $8 / 16$ & $16 / 16$ & $16 / 32$ \\
\hline
\end{tabular}

TABLE 3: MIC and MBC/MFC values of EEP and CHX on the biofilms of the test microorganisms ( $\mu \mathrm{g} / \mathrm{mL})$.

\begin{tabular}{|c|c|c|c|c|}
\hline Strains & EEP-MIC & EEP-MBC & CHX-MIC & CHX-MBC \\
\hline S. mutans & 1024 & 1024 & 1024 & 1024 \\
\hline S. sobrinus & 1024 & 1024 & 1024 & 1024 \\
\hline L. acidophilus & 512 & 512 & 512 & 1024 \\
\hline L. salivarius subsp. salivarius & 512 & 512 & 512 & 1024 \\
\hline A. actinomycetemcomitans & 128 & 256 & 64 & 128 \\
\hline P. intermedia & 128 & 256 & 256 & 512 \\
\hline P. gingivalis & 128 & 256 & 128 & 256 \\
\hline S. aureus & 128 & 256 & 64 & 128 \\
\hline E. faecalis & 64 & 128 & 16 & 32 \\
\hline A. israelii & 512 & 1024 & 1024 & 1024 \\
\hline C. albicans & 64 & 128 & 64 & 128 \\
\hline
\end{tabular}

\section{Discussion}

The results of this study indicated that both EEP and CHX had a range of inhibitory effects on the test species in their biofilm and planktonic state. In addition, this effect did not seem to be associated with the $80 \%$ ethanol in which the propolis was dissolved.

The antibacterial effects of propolis against microorganisms could be complex, leading to the disintegration of the cytoplasm, cytoplasmic membrane and cell wall, partial bacteriolysis, and inhibition of protein synthesis [23]. In a previous study, it was claimed that the $\mathrm{pH}$ and the concentration of propolis might alter due to solvents, and acidic propolis solutions were more effective on bacteria [24]. In addition, bacterial cell wall and their biofilm properties were concluded as adjunct factors, which determine bactericidal effect of propolis [25-27]. Thus, propolis could act against each microorganism in different ways.

The slight differences between our MIC/MBC values and those found in other studies are possibly owing to the differences in the strains and/or to the diverse origins of the propolis samples, since the composition of propolis depends on the regional vegetation [28]. The propolis samples obtained from poplar buds, which appear to be the dominant propolis source, in temperate zones (Asia, Europe, North
America, etc.) predominantly contain phenolic compounds, including several flavonoids, aromatic acids, and their esters [29]. Mechanisms of activity of propolis against microorganisms are still not well understood. Some components present in propolis extracts like flavonoids (quercetin, galangin, and pinocembrin) and caffeic acid, benzoic acid, and cinnamic acid probably act on the microbial cytoplasmic membrane or cell wall site, causing functional and structural damage $[28,30]$. Some authors revealed that its activity against microorganisms was more related to the synergistic effect of flavonoids (and other phenolics) than individual compounds [31]. Although our results indicated that the flavonoid content of the EEP utilized in this study was comparatively less than that reported by other studies $[7,32]$ on Turkish propolis, the cinnamic acid content was exceedingly high. This result could suggest a synergistic effect between cinnamic acid compounds and flavanoids.

Some authors stated that propolis could only be active against Gram-positive bacteria [33,34] and some fungi [10] and still according to others it is less effective against Gramnegative bacteria $[15,17]$. The MIC/MBC values determined in our study were in line with other studies stating that Grampositive bacteria were more susceptible to propolis than the Gram-negative bacteria in their planktonic state. However, the results of the analysis of the biofilms did not corroborate 
the result indicating that propolis had been more effective on Gram-positive bacteria.

Previous reports elucidated that the biofilm of cariogenic bacteria was responsible for the formation of exopolysaccharides due to glucosyltransferase enzyme activity. Therefore, it was claimed that the aforementioned bacteria were highly tolerant to environmental stresses [25-27]. Certain studies reported that propolis led to a significant reduction in dental plaque [35] and prevented caries formation [18, 36], whereas others revealed that it had no significant effect on the reformation of dental plaque [37]. The results of this study revealed that propolis might be as effective as $\mathrm{CHX}$ on cariogenic bacteria. However, our results indicated that the current concentration of EEP might not be sufficient to show bactericidal effect on cariogenic bacteria. The inconsistency between the results of our study and those of others may be related to the factors above that indicate a correlation between the constituents of propolis, their activity on different bacterial cell wall structures, and the cellular activity of cariogenic bacteria.

The studies that investigated the effect of propolis on periodontal pathogens showed similar results to our study [8, 38, 39]. However, previous studies differ from ours because they aimed to investigate the effect of propolis on planktonic bacteria. The resistance of the biofilm of periodontopathogens selected for this study has been attributed to their extra polymeric substance (EPS) and lipopolysaccharide (LPS) levels. Similar cell wall structures and EPS of these periodontopathogens may explain why EEP has shown equal $\mathrm{MIC} / \mathrm{MBC}$ values in their biofilms.

Biofilm formation of $C$. albicans is a critical issue in the treatment of Candida infections and can be a major challenge for clinicians. Biofilm resistance of $C$. albicans is not properly explained [40, 41]. It has been proffered that the biofilm resistance of propolis is not only correlated with EPS but develops over time [42] and related to the specific surfaceinduced gene expression [43]. In our study, in accordance with the results of a previous study, EEP displayed a strong antifungal activity against the Candida strain [33]. The strong activity of EEP on C. albicans may be related to its biofilm properties, which were stated in previous studies.

$\mathrm{CHX}$, which is a gold standard, was selected as a test antiseptic for this study because of its wide-range effect on several microorganisms and its property known as "substantivity." The MBC values observed for the bacteria and the fungus in their biofilm state indicated that there were no marked differences in the resistance of the biofilm of microorganisms against CHX or EPS. This result may suggest that the biofilm of tested microorganisms may respond in the same way to the current concentrations of both agents. CHX was apparently more effective on E. faecalis. Although this result was also corroborated by other studies, the studies were carried out on the planktonic form of E. faecalis [44, 45].

The main limitation of our study was the employment of MIC and MBC methods, which were performed by using broth microdilution and agar dilution techniques. While these methods are routine, unforeseen interactions between media constituents, with either one or more of the test agents, or the possible volatility of an important ingredient of the test mixture, such as alcohol, could prevent the interpretation of the results. Nonetheless, the MIC and MBC are the most reliable and easily interpreted methods for comparison of the formulations in use today [46].

\section{Conclusion}

Based on our results, we may conclude that the administration of propolis at appropriate concentrations might be effective on oral microorganisms. Although CHX is still one of the most common oral rinse products against wide range of microorganisms, EEP may serve as an alternative natural and reliable antimicrobial mouth rinse in order to avoid the side effects of CHX. In vivo studies are required to find out the effective mechanism of propolis and its appropriate administration dose on biofilm.

\section{Conflict of Interests}

The authors declare no conflict of interests.

\section{References}

[1] M. L. Barnett, "The role of therapeutic antimicrobial mouthrinses in clinical practice: control of supragingival plaque and gingivitis," Journal of the American Dental Association, vol. 134, no. 6, pp. 699-741, 2003.

[2] N. Sharma, C. H. Charles, M. C. Lynch et al., "Adjunctive benefit of an essential oil-containing mouthrinse in reducing plaque and gingivitis in patients who brush and floss regularly: a sixmonth study," Journal of the American Dental Association, vol. 135, no. 4, pp. 496-504, 2004.

[3] C. D. Overholser, T. F. Meiller, L. G. DePaola, G. E. Minah, and C. Niehaus, "Comparative effects of 2 chemotherapeutic mouthrinses on the development of supragingival dental plaque and gingivitis," Journal of Clinical Periodontology, vol. 17, no. 8, pp. 575-579, 1990.

[4] C. H. Charles, K. M. Mostler, L. L. Bartels, and S. M. Mankodi, "Comparative antiplaque and antigingivitis effectiveness of a chlorhexidine and an essential oil mouthrinse: 6-month clinical trial," Journal of Clinical Periodontology, vol. 31, no. 10, pp. 878884, 2004.

[5] A. J. Mariotti and D. A. H. Rumpf, "Chlorhexidine-induced changes to human gingival fibroblast collagen and non-collagen protein production," Journal of Periodontology, vol. 70, no. 12, pp. 1443-1448, 1999.

[6] C. A. Gürgan, E. Zaim, I. Bakirsoy, and E. Soykan, "Short-term side effects of $0.2 \%$ alcohol-free chlorhexidine mouthrinse used as an adjunct to non-surgical periodontal treatment: a doubleblind clinical study," Journal of Periodontology, vol. 77, no. 3, pp. 370-384, 2006.

[7] O. Koru, F. Toksoy, C. H. Acikel et al., "In vitro antimicrobial activity of propolis samples from different geographical origins against certain oral pathogens," Anaerobe, vol. 13, no. 3-4, pp. 140-145, 2007.

[8] F. A. Santos, E. M. A. F. Bastos, A. B. R. A. Maia et al., "Brazilian propolis: physicochemical properties, plant origin and antibacterial activity on periodontopathogens," Phytotherapy Research, vol. 17, no. 3, pp. 285-289, 2003.

[9] F. A. Santos, E. M. A. Bastos, M. Uzeda et al., "Antibacterial activity of Brazilian propolis and fractions against oral 
anaerobic bacteria," Journal of Ethnopharmacology, vol. 80, no. 1, pp. 1-7, 2002.

[10] H. Koo, B. P. F. A. Gomes, P. L. Rosalen, G. M. B. Ambrosano, Y. K. Park, and J. A. Cury, "In vitro antimicrobial activity of propolis and Arnica montana against oral pathogens," Archives of Oral Biology, vol. 45, no. 2, pp. 141-148, 2000.

[11] F. Ozan, Z. Sumer, Z. A. Polat et al., "Effect of mouthrinse containing propolis on oral microorganisms and human gingival fibroblasts," European Journal of Dentistry, vol. 1, pp. 195-201, 2007.

[12] J. R. Franca, M. P. De Luca, T. G. Ribeiro et al., "Propolisbased chitosan varnish: drug delivery, controlled release and antimicrobial activity against oral pathogen bacteria," $B M C$ Complementary and Alternative Medicine, vol. 14, article 478, 2014.

[13] N. Malhotra, S. P. Rao, S. Acharya, and B. Vasudev, "Comparative in vitro evaluation of efficacy of mouthrinses against Streptococcus mutans, Lactobacilli and Candida albicans," Oral Health \& Preventive Dentistry, vol. 9, no. 3, pp. 261-268, 2011.

[14] G. A. Burdock, "Review of the biological properties and toxicity of bee propolis (propolis)," Food and Chemical Toxicology, vol. 36, no. 4, pp. 347-363, 1998.

[15] J. M. Sforcin, A. Fernandes Jr., C. A. M. Lopes, V. Bankova, and S. R. C. Funari, "Seasonal effect on Brazilian propolis antibacterial activity," Journal of Ethnopharmacology, vol. 73, no. 1-2, pp. 243-249, 2000.

[16] S. Sonmez, L. Kirilmaz, M. Yucesoy, B. Yücel, and B. Yilmaz, "The effect of bee propolis on oral pathogens and human gingival fibroblasts," Journal of Ethnopharmacology, vol. 102, no. 3, pp. 371-376, 2005.

[17] J. W. Dobrowolski, S. B. Vohora, K. Sharma, S. A. Shah, S. A. H. Naqvi, and P. C. Dandiya, "Antibacterial, antifungal, antiamoebic, antiinflammatory and antipyretic studies on propolis bee products," Journal of Ethnopharmacology, vol. 35, no. 1, pp. 7782, 1991.

[18] K. Ikeno, T. Ikeno, and C. Miyazawa, "Effects of propolis on dental caries in rats," Caries Research, vol. 25, no. 5, pp. 347-351, 1991.

[19] B. M. Hausen, E. Wollenweber, H. Senff, and B. Post, "Propolis allergy. (I). Origin, properties, usage and literature review," Contact Dermatitis, vol. 17, no. 3, pp. 163-170, 1987.

[20] B. E. Bjorkner, "Industrial airborne dermatoses," Dermatologic Clinics, vol. 12, no. 3, pp. 501-509, 1994.

[21] Clinical and Laboratory Standards Institute, "Methods for dilution antimicrobial susceptibility tests for bacteria that grow aerobically," Approved Standard M7-A7, CLSI, Wayne, Pa, USA, 2007.

[22] Institute CaLS, "Methods for antimicrobial susceptibility testing of anaerobic bacteria," in Approved Standard M11-A7, CLSI, Wayne, Pa, USA, 2007.

[23] N. B. Takaisi-Kikuni and H. Schilcher, "Electron microscopic and microcalorimetric investigations of the possible mechanism of the antibacterial action of a defined propolis provenance," Planta Medica, vol. 60, no. 3, pp. 222-227, 1994.

[24] B. C. B. S. Mello and M. D. Hubinger, "Antioxidant activity and polyphenol contents in Brazilian green propolis extracts prepared with the use of ethanol and water as solvents in different $\mathrm{pH}$ values," International Journal of Food Science and Technology, vol. 47, no. 12, pp. 2510-2518, 2012.

[25] S. Duarte, H. Koo, W. H. Bowen et al., "Effect of a novel type of propolis and its chemical fractions on glucosyltransferases and on growth and adherence of mutans streptococci," Biological \& Pharmaceutical Bulletin, vol. 26, no. 4, pp. 527-531, 2003.

[26] J. A. Lemos and R. A. Burne, "A model of efficiency: stress tolerance by Streptococcus mutans," Microbiology, vol. 154, no. 11, pp. 3247-3255, 2008.

[27] R. G. Quivey Jr., W. L. Kuhnert, and K. Hahn, "Adaptation of oral streptococci to low $\mathrm{pH}$," Advances in Microbial Physiology, vol. 42, pp. 239-274, 2000.

[28] M. C. Marcucci, "Propolis: chemical composition, biological properties and therapeutic activity," Apidologie, vol. 26, no. 2, pp. 83-99, 1995.

[29] F. A. Tomás-Barberán, C. García-Viguera, P. Vit-Olivier, F. Ferreres, and F. Tomás-Lorente, "Phytochemical evidence for the botanical origin of tropical propolis from Venezuela," Phytochemistry, vol. 34, no. 1, pp. 191-196, 1993.

[30] O. K. Mirzoeva, R. N. Grishanin, and P. C. Calder, "Antimicrobial action of propolis and some of its components: the effects on growth, membrane potential and motility of bacteria," Microbiological Research, vol. 152, no. 3, pp. 239-246, 1997.

[31] M. Amoros, E. Lurton, J. Boustie, L. Girre, F. Sauvager, and M. Cormier, "Comparison of the anti-herpes simplex virus activities of propolis and 3-methyl-but-2-enyl caffeate," Journal of Natural Products, vol. 57, no. 5, pp. 644-647, 1994.

[32] A. Uzel, K. Sorkun, Ö. Önçă̆, D. Çoğulu, Ö. Gençay, and B. Salih, "Chemical compositions and antimicrobial activities of four different Anatolian propolis samples," Microbiological Research, vol. 160, no. 2, pp. 189-195, 2005.

[33] A. Kujumgiev, I. Tsvetkova, Y. Serkedjieva, V. Bankova, R. Christov, and S. Popov, "Antibacterial, antifungal and antiviral activity of propolis of different geographic origin," Journal of Ethnopharmacology, vol. 64, no. 3, pp. 235-240, 1999.

[34] M. I. Nieva Moreno, M. I. Isla, N. G. Cudmani, M. A. Vattuone, and A. R. Sampietro, "Screening of antibacterial activity of Amaicha del Valle (Tucumán, Argentina) propolis," Journal of Ethnopharmacology, vol. 68, no. 1-3, pp. 97-102, 1999.

[35] H. Koo, J. A. Cury, P. L. Rosalen, G. M. B. Ambrosano, M. Ikegaki, and Y. K. Park, "Effect of a mouthrinse containing selected propolis on 3-day dental plaque accumulation and polysaccharide formation," Caries Research, vol. 36, no. 6, pp. 445-448, 2002.

[36] M. F. Hayacibara, H. Koo, P. L. Rosalen et al., "In vitro and in vivo effects of isolated fractions of Brazilian propolis on caries development," Journal of Ethnopharmacology, vol. 101, no. 1-3, pp. 110-115, 2005.

[37] M. C. Murray, H. V. Worthington, and A. S. Blinkhorn, "A study to investigate the effect of a propolis-containing mouthrinse on the inhibition of de novo plaque formation," Journal of Clinical Periodontology, vol. 24, no. 11, pp. 796-798, 1997.

[38] G. Agarwal, G. Vemanaradhya, and D. Mehta, "Evaluation of chemical composition and efficacy of Chinese propolis extract on Porphyromonas gingivalis and Aggregatibacter actinomycetemcomitans: an in vitro study," Contemporary Clinical Dentistry, vol. 3, no. 3, pp. 256-261, 2012.

[39] F. A. Santos, E. M. A. Bastos, P. H. Rodrigues et al., "Susceptibility of Prevotella intermedia/Prevotella nigrescens (and Porphyromonas gingivalis) to propolis (bee glue) and other antimicrobial agents," Anaerobe, vol. 8, no. 1, pp. 9-15, 2002.

[40] B. Adam, G. S. Baillie, and L. J. Douglas, "Mixed species biofilms of Candida albicans and Staphylococcus epidermidis," Journal of Medical Microbiology, vol. 51, no. 4, pp. 344-349, 2002.

[41] K. Lewis, "Riddle of biofilm resistance," Antimicrobial Agents and Chemotherapy, vol. 45, no. 4, pp. 999-1007, 2001. 
[42] J. Chandra, D. M. Kuhn, P. K. Mukherjee, L. L. Hoyer, T. McCormick, and M. A. Ghannoum, "Biofilm formation by the fungal pathogen Candida albicans: development, architecture, and drug resistance," Journal of Bacteriology, vol. 183, no. 18, pp. 5385-5394, 2001.

[43] G. S. Baillie and L. J. Douglas, "Matrix polymers of Candida biofilms and their possible role in biofilm resistance to antifungal agents," Journal of Antimicrobial Chemotherapy, vol. 46, no. 3, pp. 397-403, 2000.

[44] J. B. Carbajal Mejía, "Antimicrobial effects of calcium hydroxide, chlorhexidine, and propolis on Enterococcus faecalis and Candida albicans," Journal of Investigative and Clinical Dentistry, vol. 5, no. 3, pp. 194-200, 2014.

[45] G. Kayaoglu, H. Ömürlü, G. Akca et al., "Antibacterial activity of propolis versus conventional endodontic disinfectants against Enterococcus faecalis in infected dentinal tubules," Journal of Endodontics, vol. 37, no. 3, pp. 376-381, 2011.

[46] A. D. Haffajee, T. Yaskell, and S. S. Socransky, "Antimicrobial effectiveness of an herbal mouthrinse compared with an essential oil and a chlorhexidine mouthrinse," Journal of the American Dental Association, vol. 139, no. 5, pp. 606-611, 2008. 

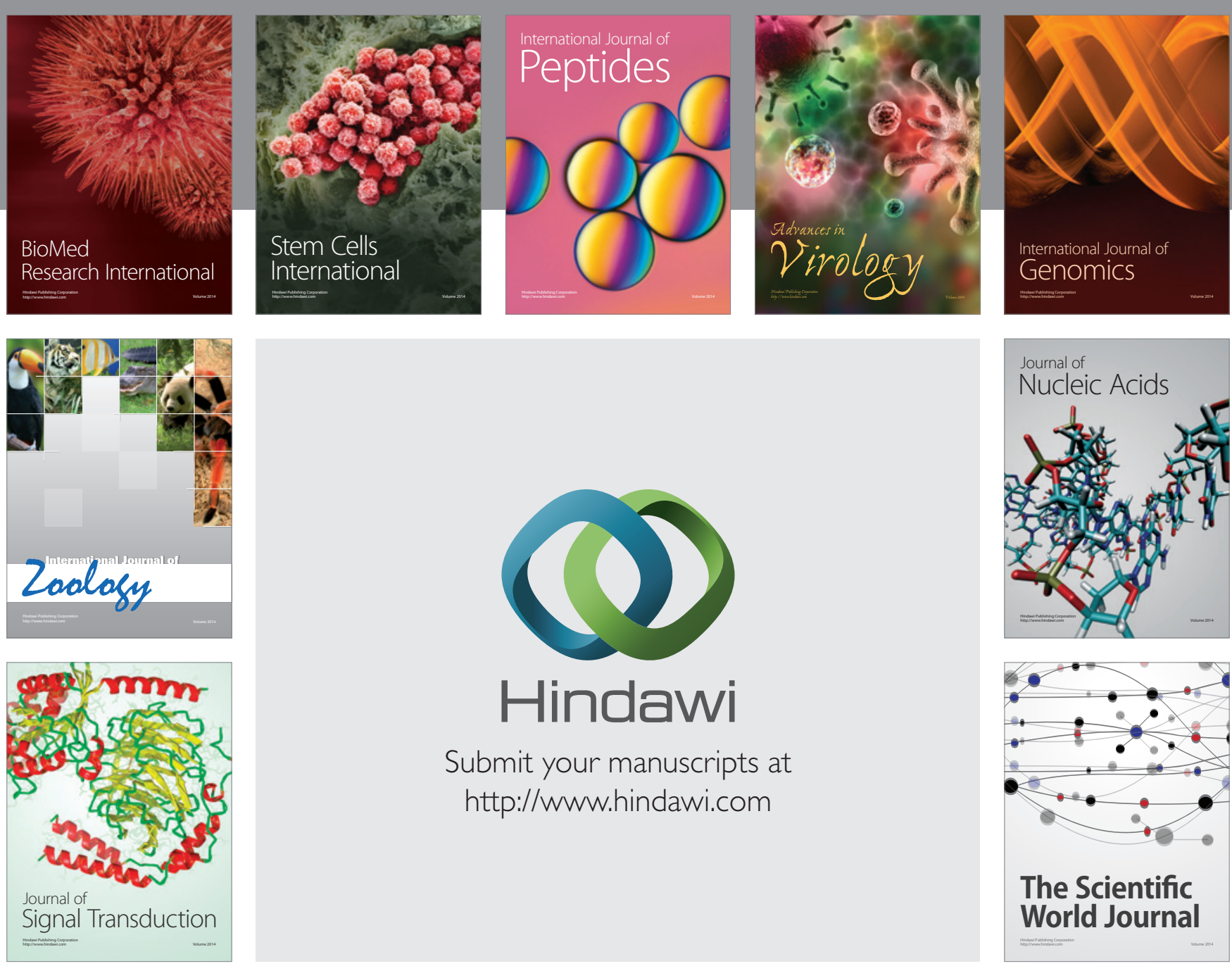

Submit your manuscripts at

http://www.hindawi.com
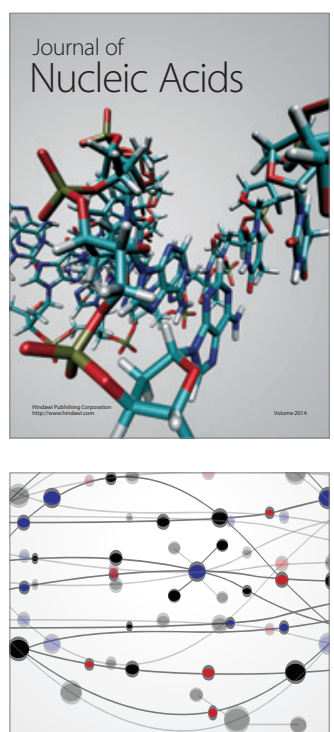

The Scientific World Journal
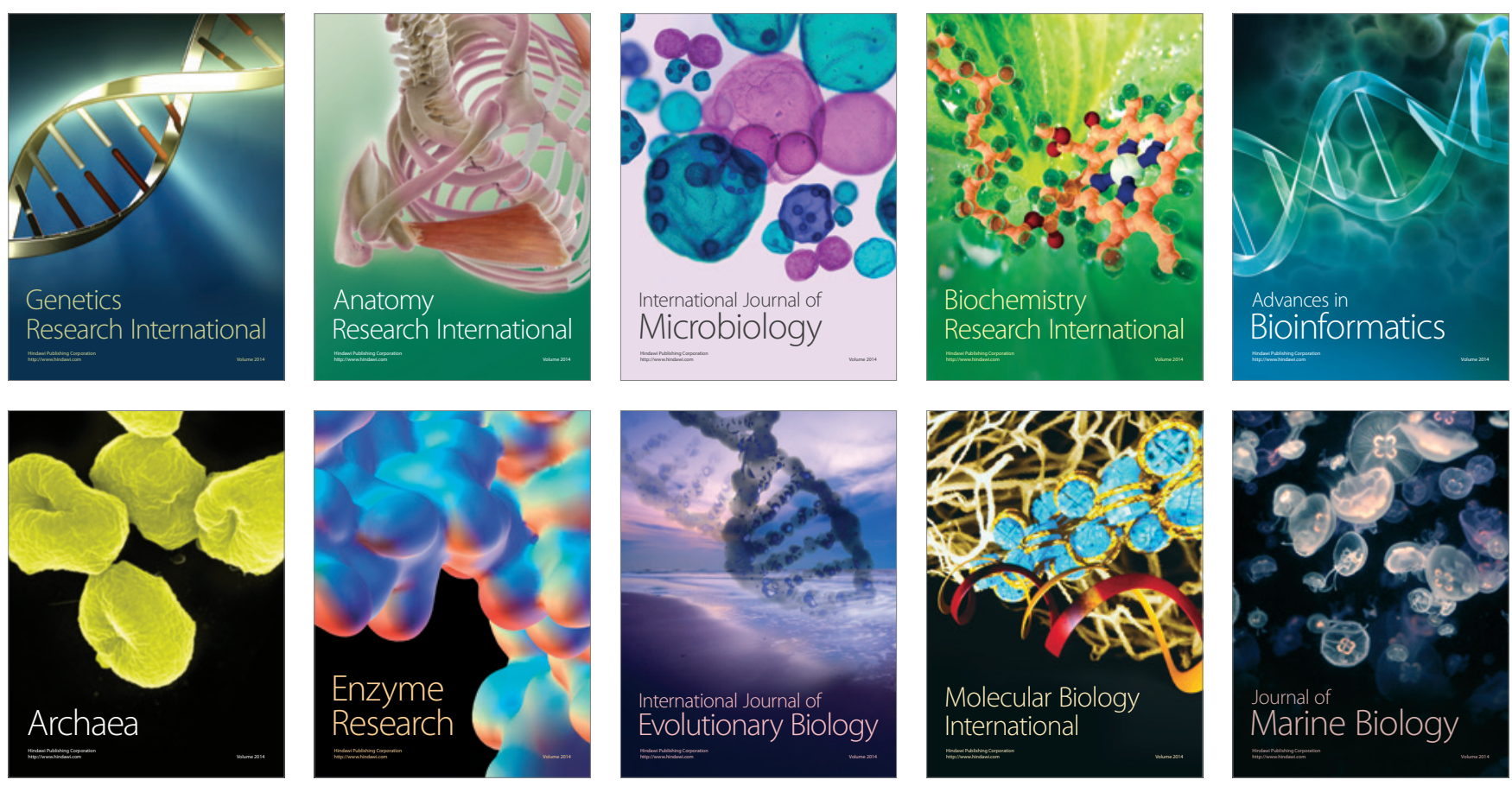